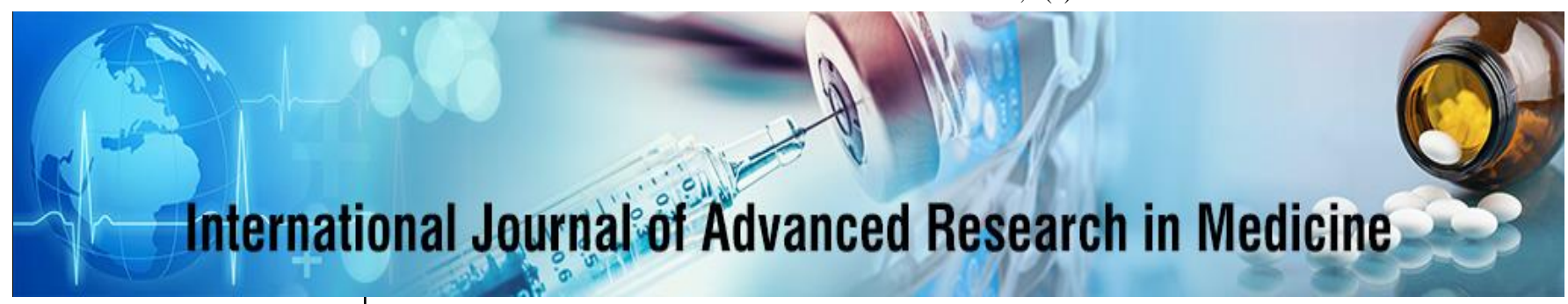

E-ISSN: 2706-9575

P-ISSN: 2706-9567

IJARM 2020; 2(2): 251-253

Received: 12-02-2020

Accepted: 21-04-2020

Dr. Sachin Raj Kumar

Associate Professor, Department

of Ophthalmology, Srinivas

Institute of Medical Sciences,

Mangalore, Karnataka, India

Dr. Roopashree

Assistant Professor, Department of Ophthalmology, Srinivas

Institute of Medical Sciences,

Mangalore, Karnataka, India
Corresponding Author:

Dr. Roopashree

Assistant Professor, Department

of Ophthalmology, Srinivas

Institute of Medical Sciences,

Mangalore, Karnataka, India

\section{A study of strabismus: Symptoms, pathophysiology and management}

\author{
Dr. Sachin Raj Kumar and Dr. Roopashree \\ DOI: https://doi.org/10.22271/27069567.2020.v2.i2d.82
}

\begin{abstract}
Strabismus is a visual disorder where the eyes are misaligned and point in different directions. This misalignment may be constantly present, or it may come and go. The four rectus muscles move the eyes up, down, to the right, and to the left, and the two oblique muscles have more complex actions, helping the eyes to look down and in (towards the tip of the nose) or up and in (towards the bridge of the nose). There a plethora of causes which disturbs this minute balance and this study intends to throw some light on this topic.
\end{abstract}

Keywords: Strabismus, symptoms, pathophysiology

\section{Introduction}

Strabismus is a visual disorder where the eyes are misaligned and point in different directions. This misalignment may be constantly present, or it may come and go. The four rectus muscles move the eyes up, down, to the right, and to the left, and the two oblique muscles have more complex actions, helping the eyes to look down and in (towards the tip of the nose) or up and in (towards the bridge of the nose) ${ }^{[1]}$. Sometimes, only one eye is affected - turning inward (esotropia), outward (exotropia) or downward - while the other eye is directed straight ahead. Strabismus can also be described by its cause. The 3 cranial nerves (III, IV, VI) responsible for eye movement can be weak or paralyzed and cause strabismus. Some examples of paralytic strabismus include third nerve palsy and superior oblique palsy ${ }^{[2]}$. Strabismus prevents proper binocular vision and prevents both eyes from gazing the same point. Either peripheral vision or side vision may be affected. A patient's perception of depth is distorted. Perception of depth is the ability to recognize the order of objects in three dimensions. Patients will also experience a limited field of view. Some common terms for strabismus are "cross eyed," which means that one or both eyes turn toward your child's nose or "wall eyed," which means one or both eyes turn out toward your child's ears ${ }^{[3]}$.

\section{Aims and Objectives}

To study the Symptoms, Pathophysiology and Management of strabismus.

\section{Materials and Methods}

The study was conducted in Srinivas Institute of Medical Sciences. This study was conducted in 30 patients who were having strabismus.

The study was done from Oct 2018 to Sept 2019.

\section{Inclusion Criteria}

All cases with strabismus with symptoms were included.

\section{Exclusion Criteria}

On steroid and chemo therapy.

On Immuno-modulator therapy

Had known ocular pathology.

Had muscle pathology. 


\section{Results}

Table 1: Age Distribution

\begin{tabular}{|l|l|}
\hline $10-20$ years & 13 \\
\hline $21-30$ years & 11 \\
\hline $31-40$ years & 04 \\
\hline $41-50$ years & 02 \\
\hline
\end{tabular}

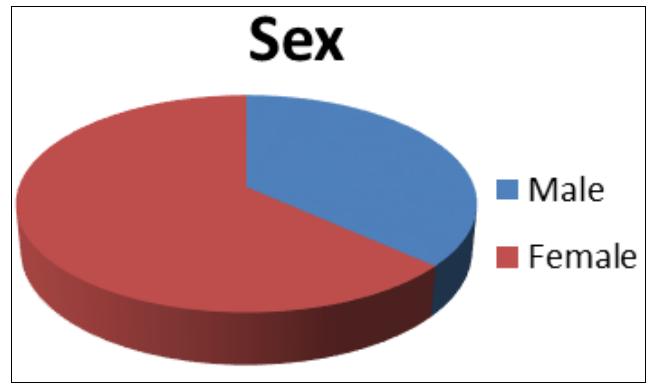

Fig 1: Sex Distribution:

Table 2: Signs and Symptoms

\begin{tabular}{|c|c|}
\hline Misalignment & 29 \\
\hline Double Vision & 28 \\
\hline Headaches & 30 \\
\hline Unstable vision & 30 \\
\hline
\end{tabular}

Table 3: Pathophysiology

\begin{tabular}{|c|c|}
\hline Eye or head injuries & 02 \\
\hline $\begin{array}{c}\text { Diseases that affect the nerves or muscles } \\
\text { such as cerebral palsy or Down syndrome }\end{array}$ & 16 \\
\hline Brain tumors & 01 \\
\hline No Specific History & 11 \\
\hline
\end{tabular}

Table 4: Management

\begin{tabular}{|c|c|}
\hline Eye patch therapy & 07 \\
\hline Eye glasses correction & 16 \\
\hline Visual Therapy & 30 \\
\hline Surgery & 03 \\
\hline
\end{tabular}

\section{Discussion}

Strabismus (crossed eyes) is a condition in which the eyes do not line up with one another. In other words, one eye is turned in a direction that is different from the other eye.

Under normal conditions, the six muscles that control eye movement work together and point both eyes at the same direction. Patients with strabismus have problems with the control of eye movement and cannot keep normal ocular alignment (eye position).

Strabismus can be categorized by the direction of the turned or misaligned eye:

- Inward turning (esotropia)

- Outward turning (exotropia)

- Upward turning (hypertropia)

- Downward turning (hypotropia)

\section{There are several forms of strabismus. The two most} common are

- Accommodative esotropia: This often occurs in cases of uncorrected farsightedness and a genetic predisposition (family history) for the eyes to turn in. Because the ability to focus is linked to where the eyes are pointing, the extra focusing effort needed to keep distant objects in clear focus may cause the eyes to turn inward. Symptoms include double vision, closing or covering one eye when looking at something near, and tilting or turning the head. This type of strabismus typically starts in the first few years of life. This condition is usually treated with glasses, but may also require eye patching and/or surgery on the muscles of one or both eyes.

- Intermittent exotropia: In this type of strabismus, one eye will fixate (concentrate) on a target while the other eye is pointing outward. Symptoms may include double vision, headaches, difficulty reading, eyestrain, and closing one eye when viewing far away objects or when in bright light. Patients may have no symptoms while the ocular deviation (difference) may be noticed by others. Intermittent exotropia can happen at any age. Treatment may involve glasses, patching, eye exercises and/or surgery on the muscles of one or both eyes.

Most strabismus results from an abnormality of the neuromuscular control of eye movement. Our understanding of these control centers in the brain is still evolving. Less commonly, there is a problem with the actual eye muscle. Strabismus is often inherited, with about 30 percent of children with strabismus having a family member with a similar problem.

\section{Other conditions associated with strabismus include}

- Uncorrected refractive errors

- Poor vision in one eye

- Cerebral palsy

- Down syndrome (20-60\% of these patients are affected)

- Hydrocephalus (a congenital disease that results in a buildup of fluid in the brain)

- Brain tumors

- Stroke (the leading cause of strabismus in adults)

- Head injuries, which can damage the area of the brain responsible for control of eye movement, the nerves that control eye movement, and the eye muscles

- Neurological (nervous system) problems

- Graves' disease (overproduction of thyroid hormone)

\section{Conclusion}

This study successfully sheds some light on the various symptoms, signs, pathophysiology and management of the strabismus.

\section{References}

1. Guyton DL. Ocular torsion reveals the mechanisms of cyclovertical strabismus The Weisenfeld Lecture. Investigative ophthalmology \& visual science 2008;49(3):847-857.

2. Katzin HM, Wilson G. Strabismus in childhood. CV Mosby Co 1968.

3. Leigh RJ, Zee DS. The neurology of eye movements. Oxford University Press 2015.

4. Paul TO, Hardage LK. The heritability of strabismus. Ophthalmic genetics 1994;15(1):1-18.

5. Chew E. et al. Risk factors for esotropia and exotropia. Archives of ophthalmology 1994;112(10):1349-1355.

6. Matsuo T, Yamane T, Ohtsuki H. Heredity versus abnormalities in pregnancy and delivery as risk factors for different types of comitant strabismus. Journal of pediatric ophthalmology and strabismus 2001;38(2):78. 
7. Emmett T, Cunningham PRE. Vaughan \& Asbury's general ophthalmology. 18th ed., Medica: McGrawHill.

8. Olson $\mathrm{JH}$, et al., Congenital esotropia and the risk of mental illness by early adulthood. Ophthalmology 2012; 119(1):145-149.

9. Beauchamp GR. et al., The utility of strabismus in adults. Transactions of the American Ophthalmological Society 2005;103:164.

10. Martinez-Thompson JM, et al., Incidence, types, and lifetime risk of adult-onset strabismus. Ophthalmology 2014;121(4):877-882.

11. Yorston DH, McGavin DM, Ophthalmology in the Tropics and Subtropics. Manson's tropical diseases. Amsterdam: Saunders Elsevier, 2009,283-332.

12. Finlay AL. Binocular vision and refractive surgery. Contact Lens and Anterior Eye 2007;30(2):76-83.

13. Derner JL, Miller JM, Poukens V. Surgical implications of the rectus extraocular muscle pulleys. J Pediatr Ophthalmol Strabismus 1996;33:208-218.

14. Yeung J. Management of Strabismus. Medical Bulletin, Hong Kong Medical Society 2010.

15. Biglan AW, et al., Management of strabismus with botulinum A toxin. Ophthalmology 1989;96(7):935943. 